\title{
Article
}

\section{The Regulation of $\mathrm{O}_{2}$ Spin State and Direct Oxidation of $\mathrm{CO}$ at Room Temperature Using Triboelectric Plasma by Harvesting Mechanical Energy}

\author{
Xue Shi ${ }^{1,+}$, Sumin $\mathrm{Li}^{1,+}$, Bao Zhang ${ }^{1,+}{ }^{\dagger}$, Jiao Wang ${ }^{1}$, Xiaochen Xiang ${ }^{1}$, Yifei Zhu ${ }^{2}$, Ke Zhao ${ }^{1}$, Wanyu Shang ${ }^{1}$, \\ Guangqin Gu ${ }^{1}$, Junmeng Guo ${ }^{1}$, Peng Cui ${ }^{1}$, Gang Cheng ${ }^{1, *}$ and Zuliang Du ${ }^{1}$ \\ 1 Key Lab for Special Functional Materials, Ministry of Education, National \& Local Joint Engineering Research \\ Center for High-Efficiency Display and Lighting Technology, School of Materials Science and Engineering, \\ Collaborative Innovation Center of Nano Functional Materials and Applications, Henan University, \\ Kaifeng 475004, China; shixuehenandaxue@126.com (X.S.); amernsuli1981@163.com (S.L.); \\ zhangbao@henu.edu.cn (B.Z.); 13203449093@163.com (J.W.); xiang17737488621@163.com (X.X.); \\ kezhao_5@163.com (K.Z.); shangwanyu0525@163.com (W.S.); guguangqin@vip.henu.edu.cn (G.G.); \\ junmengguo@163.com (J.G.); cuipeng@henu.edu.cn (P.C.); zld@henu.edu.cn (Z.D.) \\ 2 Institute of Aero-Engine, School of Mechanical Engineering, Xi'an Jiaotong University, Xi'an 710049, China; \\ yifei.zhu.plasma@gmail.com \\ * Correspondence: chenggang@henu.edu.cn \\ check for
} updates

Citation: Shi, X.; Li, S.; Zhang, B.; Wang, J.; Xiang, X.; Zhu, Y.; Zhao, K.; Shang, W.; Gu, G.; Guo, J.; et al. The Regulation of $\mathrm{O}_{2}$ Spin State and Direct Oxidation of $\mathrm{CO}$ at Room Temperature Using Triboelectric Plasma by Harvesting Mechanical Energy. Nanomaterials 2021, 11, 3408. https://doi.org/10.3390/ nano11123408

Academic Editors: Zhen Wen, Hengyu Guo, Longfei Wang and Detlef W. Bahnemann

Received: 16 November 2021 Accepted: 13 December 2021 Published: 16 December 2021

Publisher's Note: MDPI stays neutral with regard to jurisdictional claims in published maps and institutional affiliations.

Copyright: () 2021 by the authors. Licensee MDPI, Basel, Switzerland. This article is an open access article distributed under the terms and conditions of the Creative Commons Attribution (CC BY) license (https:// creativecommons.org/licenses/by/ $4.0 /)$.

\begin{abstract}
Oxidation reactions play a critical role in processes involving energy utilization, chemical conversion, and pollutant elimination. However, due to its spin-forbidden nature, the reaction of molecular dioxygen $\left(\mathrm{O}_{2}\right)$ with a substrate is difficult under mild conditions. Herein, we describe a system that activates $\mathrm{O}_{2}$ via the direct modulation of its spin state by mechanical energy-induced triboelectric corona plasma, enabling the $\mathrm{CO}$ oxidation reaction under normal temperature and pressure. Under optimized reaction conditions, the activity was $7.2 \mu \mathrm{mol} \mathrm{h}{ }^{-1}$, and the energy consumption per mole CO was 4.2 MJ. The results of kinetic isotope effect, colorimetry, and density functional theory calculation studies demonstrated that electrons generated in the triboelectric plasma were directly injected into the antibonding orbital of $\mathrm{O}_{2}$ to form highly reactive negative ions $\mathrm{O}_{2}{ }^{-}$, which effectively promoted the rate-limiting step of $\mathrm{O}_{2}$ dissociation. The barrier of the reaction of $\mathrm{O}_{2}{ }^{-}$ions and $\mathrm{CO}$ molecular was $3.4 \mathrm{eV}$ lower than that of $\mathrm{O}_{2}$ and $\mathrm{CO}$ molecular. This work provides an effective strategy for using renewable and green mechanical energy to realize spin-forbidden reactions of small molecules.
\end{abstract}

Keywords: triboelectric nanogenerator; mechanical energy; dioxygen activation; triboelectric corona plasma; $\mathrm{O}_{2}{ }^{-}$reactive species; spin conversion

\section{Introduction}

Molecular dioxygen $\left({ }^{3} \mathrm{O}_{2}\right)$ is the most green, pollution-free, and cheap terminal oxidant [1-8]. Unfortunately, ground state ${ }^{3} \mathrm{O}_{2}$ is usually chemically inert under normal temperature and pressure conditions, and the oxidation of compounds by ${ }^{3} \mathrm{O}_{2}$ is hindered by its spin-forbidden nature [1]. To enable the activation of ${ }^{3} \mathrm{O}_{2}$ at room temperature, considerable research efforts have been directed toward the regulation of its spin state. As a result, a number of approaches have been developed, such as the conversion of the triplet state of dioxygen $\left({ }^{3} \mathrm{O}_{2}\right)$ into singlet dioxygen $\left({ }^{1} \mathrm{O}_{2}\right)$ via external stimulation, e.g., by light irradiation $[2,3,9,10]$. This can be achieved under the assistance of a photosensitizer, as shown in Figure 1a. Under light illumination, the photosensitizer absorbs energy and is excited to an excited single state, which then undergoes intersystem crossing to produce an excited triplet state. The latter transfers its energy to ${ }^{3} \mathrm{O}_{2}$, which is converted to ${ }^{1} \mathrm{O}_{2}$, while the excited photosensitizer returns to its ground state. The two spin-paired valence 
electrons of ${ }^{1} \mathrm{O}_{2}$ are in one $\pi$ orbital, while the second $\pi^{*}$ orbital is empty, thereby lifting the spin blockade of ${ }^{3} \mathrm{O}_{2}$. Another method for the activation of ${ }^{3} \mathrm{O}_{2}$ consists of its one-electron reduction to superoxide ${ }^{2} \mathrm{O}_{2}{ }^{-}$(Figure $1 \mathrm{~b}$ ) [2,4-8], in which the electron is transferred to the ${ }^{3} \mathrm{O}_{2}$ molecule via metal/metal oxide catalysis or photocatalysis. The lowest unoccupied molecular orbital (LUMO) $\pi^{*}$ of ${ }^{2} \mathrm{O}_{2}{ }^{-}$has a single electron, which endows the molecule with free radical reactivity, easily reacting with a substrate. Nevertheless, both ${ }^{3} \mathrm{O}_{2}$ activation systems require the use of metals or metal oxides as catalysts or additives [1-5,11-15], with the concomitant heavy metal pollution and economic infeasibility of large-scale production. Thus, the development of an efficient system for the activation of ${ }^{3} \mathrm{O}_{2}$ for aerobic oxidation via the direct regulation of its spin state is still a huge challenge.

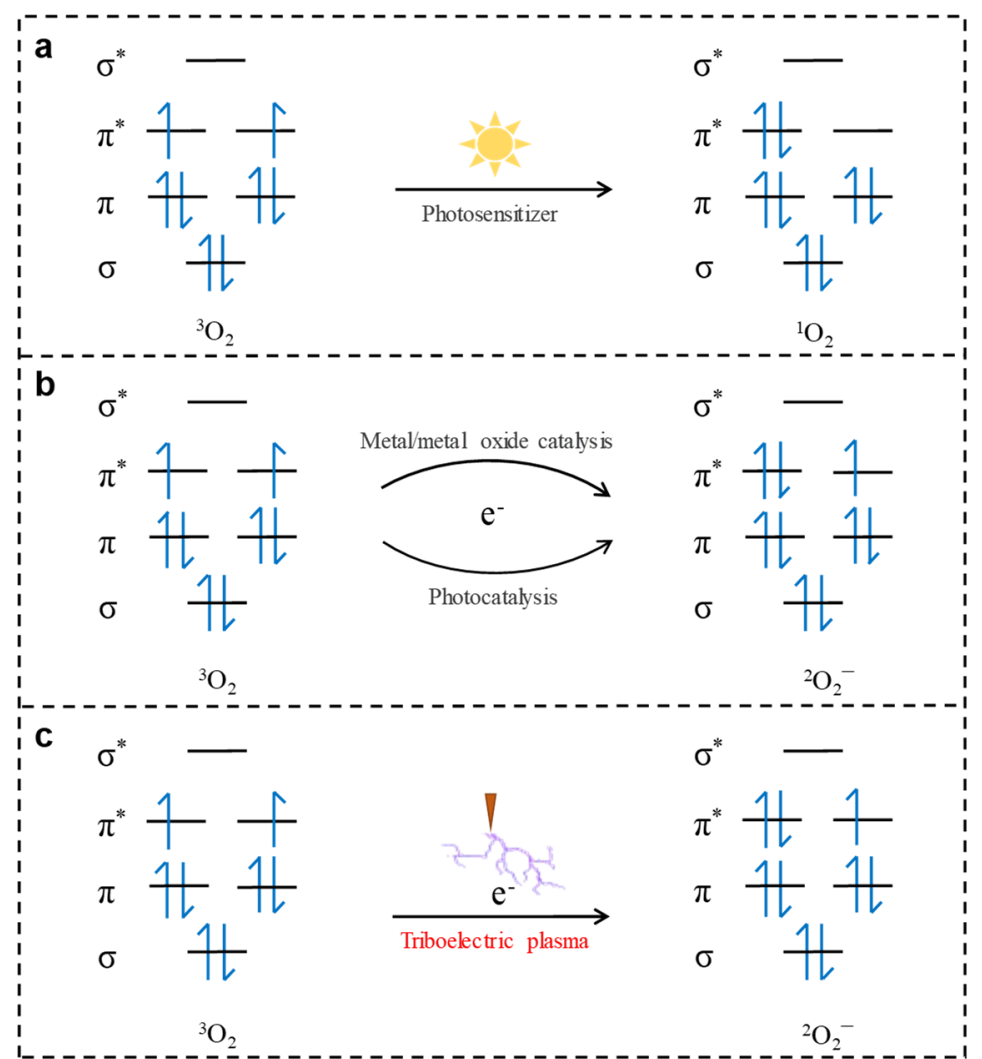

Figure 1. Spins conversion of molecular dioxygen using different methods. (a) Transformation of ${ }^{3} \mathrm{O}_{2}$ to ${ }^{1} \mathrm{O}_{2}$ under light irradiation with a photosensitizer. (b) Transformation of ${ }^{3} \mathrm{O}_{2}$ to ${ }^{2} \mathrm{O}_{2}{ }^{-}$ under metal/metal oxide catalysis and photocatalysis. (c) Transformation of ${ }^{3} \mathrm{O}_{2}$ to ${ }^{2} \mathrm{O}_{2}{ }^{-}$using triboelectric plasma.

In this context, mechanical energy can be envisaged as an attractive source of activation energy because it is a ubiquitous, earth-abundant, and renewable energy that exists in various forms including wind energy, raindrop energy, tidal energy, and hydropower [16-23]. Compared with other renewable energy sources such as solar energy, mechanical energy offers the advantage of abundant reserves that are not affected by geographical location and weather $[24,25]$. In recent years, triboelectric nanogenerators (TENGs) have emerged as novel mechanical energy collection devices with broad application prospects in energy collection [26], gas sensing [27], and other fields [25,28,29]. A TENG is characterized by an advantageous high output voltage, which can directly generate a gas discharge forming triboelectric plasma $[30,31]$. During such a process, a large number of electrons generated through the avalanche effect can be captured by electronegative ${ }^{3} \mathrm{O}_{2}$ molecules; hence, electrons are injected into the LUMO energy level of ${ }^{3} \mathrm{O}_{2}$, enabling its conversion into ${ }^{2} \mathrm{O}_{2}{ }^{-}$. Therefore, numerous electrons generated in the mechanical energy-induced triboelectric 
plasma are directly transferred into the LUMO energy level of ${ }^{3} \mathrm{O}_{2}$, which is expected to overcome the spin-forbidden nature of its activation at room temperature (Figure 1c).

Herein, we report the use of triboelectric corona plasma for the direct modulation of the spin state of ${ }^{3} \mathrm{O}_{2}$, which enabled its activation for the direct carbon monoxide (CO) oxidation at room temperature and pressure. We selected the $\mathrm{CO}$ oxidation reaction as a model reaction to study the effect of ${ }^{3} \mathrm{O}_{2}$ spin change on its reactivity because it is a common model reaction of great significance in the fields of automobile exhaust treatment, fuel cells, and environmental protection. We used the high output voltage of a TENG to trigger the generation of triboelectric plasma from a gas and investigated the influence of the rotational speed of the TENG, the needle-plate distance, and the corona polarity on the triboelectric plasma. The optimal activity was $7.2 \mu \mathrm{mol} \mathrm{h}^{-1}$, and the minimum energy required to convert $1 \mathrm{~mol} \mathrm{CO}$ was $4.2 \mathrm{MJ}$. The results of colorimetry, kinetic isotope effect (KIE), and density functional theory (DFT) studies showed that high-energy electrons generated in the triboelectric plasma were directly injected into the $\pi^{*}$ antibonding orbital of ${ }^{3} \mathrm{O}_{2}$ to realize the activation of the $\mathrm{O}-\mathrm{O}$ bonds at low temperature. This work provides a novel pathway for using mechanical energy to overcome the spin-forbidden transition of small molecules.

\section{Materials and Methods}

\subsection{Carbon Monoxide (CO) Oxidation Triggered by Mechanical Energy-Induced Triboelectric Plasma}

The system for the triboelectric plasma-triggered $\mathrm{CO}$ oxidation consisted of three parts: a TENG, a plasma oxidation reaction device, and an electrical test system. The freestanding rotating TENG with a diameter of $25 \mathrm{~cm}$ was composed of $10 \mu \mathrm{m}$ of polytetrafluoroethylene (PTFE) film and a $30 \mu \mathrm{m} \mathrm{Cu}$ film as triboelectric layers and an electrode. The $\mathrm{Cu}$ and PTFE layers were adhered to polymethylmethacrylate. Two $\mathrm{Cu}$ films were connected to form the TENG electrodes through a rectifier bridge of the external circuit using $\mathrm{Cu}$ wires. When the triboelectric layers of the TENG were in contact with each other, opposite triboelectric charges were generated. When the PTFE triboelectric layer was moving, the two $\mathrm{Cu}$ electrodes generated a potential difference. The electrode of the triboelectric plasma was composed of a W needle and a Pt electrode plate. The radius of curvature of the $\mathrm{W}$ needle was $5 \mu \mathrm{m}$. The two discharge electrodes were located in a $500 \mathrm{~mL}$ reaction bottle, and the distance between the $\mathrm{W}$ needle and the Pt electrode plate was precisely adjusted using a three-dimensional moving platform.

The triboelectric plasma-triggered $\mathrm{CO}$ oxidation reaction was conducted in a self-made glass reactor $(500 \mathrm{~mL})$ under normal temperature and pressure. Using the TENG as the driving force, the output signal was recorded in an ammeter (Keithley 6514) and a voltmeter (Tektronix). The W needle and the Pt electrode plate (Tianjin Aida Hengsheng Technology Development Co., Ltd.,Tianjin, China, purity $99.99 \%$ ) were fixed in the glass reactor, which then was purged with a mixed gas of $\mathrm{CO} / \mathrm{O}_{2} / \mathrm{He}$ (1:20:79) (Henan Yuan Zheng Technology Development Co., Ltd., Kaifeng, China) for $10 \mathrm{~min}$, and the air was replaced with the mixed gas three times. During the reaction, a carbon dioxide $\left(\mathrm{CO}_{2}\right)$ detector was used to determine the $\mathrm{CO}_{2}$ concentration generated (Haipa air detector, accuracy $1 \mathrm{ppm}$ ), the reaction time was set to $1 \mathrm{~h}$, the needle-plate distance was $3 \mathrm{~mm}$, and the rotational speed of the TENG was $400 \mathrm{rpm}$. The effects of rotational speed of the TENG, needle-plate distance, the corona polarities, and working electrodes on the $\mathrm{CO}$ oxidation reaction activity were investigated.

\subsection{Detection of ${ }^{2} \mathrm{O}_{2}{ }^{-}$Radicals}

Nitro blue tetrazolium (NBT; Shandong West Asia Chemical Co., Ltd., Dongying, China) was reduced by $\mathrm{O}_{2}{ }^{-}$radicals to produce a blue product, which was insoluble in water [32]. The change in the absorbance of the solution was measured using ultravioletvisible spectroscopy to detect the existence of reactive $\mathrm{O}_{2}{ }^{-}$radicals. The NBT aqueous solution had a maximum absorption peak at a wavelength of $260 \mathrm{~nm}$. In a $3 \mathrm{~mL}$ glass reaction device, $2 \mathrm{~mL}$ of a $0.05 \mathrm{mmol} \mathrm{L}{ }^{-1} \mathrm{NBT}$ solution $\left(\mathrm{V}_{\text {water }}: \mathrm{V}_{\text {propanol }}=98: 2\right)$ was added. 
A $\mathrm{Cu}$ mesh electrode was placed above the solution surface to avoid the quenching of highly energetic radicals, purged with $\mathrm{CO} / \mathrm{O}_{2} / \mathrm{He}$ mixed gas, and then discharged for $30 \mathrm{~min}$.

\subsection{Isotope Labeling Experiment}

The triboelectric plasma-triggered $\mathrm{CO}$ oxidation reaction was performed using ${ }^{13} \mathrm{CO} /{ }^{18} \mathrm{O}_{2} / \mathrm{Ar}$ and ${ }^{12} \mathrm{CO} /{ }^{16} \mathrm{O}_{2} / \mathrm{Ar}$ for $10 \mathrm{~h}$. The composition and concentration of the isotopic products were determined by Wuhan Newrad Special Gas Co., Ltd., Wuhan, China.

\subsection{Isotope Kinetics Effect (KIE) Experiment}

The KIE experiments were conducted using $\mathrm{CO} /{ }^{16} \mathrm{O}_{2} / \mathrm{He}$ and $\mathrm{CO} /{ }^{18} \mathrm{O}_{2} / \mathrm{He}$ as the substrates under the conditions of the triboelectric plasma-triggered $\mathrm{CO}$ oxidation reaction for $1 \mathrm{~h}$ at room temperature and pressure. The KIE was calculated on the basis of the reaction rates obtained using ${ }^{16} \mathrm{O}_{2}$ and ${ }^{18} \mathrm{O}_{2}$ as reactants.

\subsection{Density Functional Theory (DFT) Calculations}

DFT calculations were performed using the Vienna Ab-initio Simulation Package (VASP) [33,34], taking advantage of the Projected Augmented Wave (PAW) [35] method. The Perdew-Burke-Ernzerhof functional was used to describe the exchange and correlation effects [36]. For all the geometry optimizations, the cutoff energy was set to $450 \mathrm{eV}$. Spinpolarization calculations were included in all cases. Singlet and triplet oxygen were modeled by controlling the numerical difference between spin-up electrons and spin-down electrons. The simulation box was constructed as a $21 \AA \times 22 \AA \times 20 \AA$ box. The DFT calculation process was provided by the Cailiaoren APP.

\subsection{Triboelectric Plasma Simulation}

Triboelectric plasma simulation was performed using 2D PASSKEy code (PArallel Streamer Solver with KinEtics), which was used in modelling nanosecond surface discharges and proved by discharge morphology, propagation velocity, voltage-current curves of triboelectric plasma, and a point-to-plane configuration generated from the experiments [37-40]. Moreover, 0D model global plasma chemistry code ZDPlasKin was also utilized in a house parameter reconstruction module [41].

\section{Results and Discussion}

\subsection{CO Oxidation System Driven by Mechanical Energy-Induced Triboelectric Plasma}

As shown in Figure 2a and Figure S1, the designed system for $\mathrm{CO}$ oxidation driven by mechanical energy-induced triboelectric plasma consisted of three parts: a TENG, a plasma oxidation reaction device, and an electrical test system. The TENG, which was composed of a Cu film and a polytetrafluoroethylene (PTFE) film friction layer, was used as the driving force of the reaction. The plasma oxidation reaction device comprised a needleplate electrode and a $\mathrm{CO}$ mixture gas $\left(\mathrm{CO} / \mathrm{O}_{2} / \mathrm{He}=1: 20: 79\right)$. The electrical test system consisted of a voltmeter and an ammeter. When the PTFE film was placed in contact with the $\mathrm{Cu}$ film, the surfaces of the two materials generated an equal amount of negative and positive triboelectric charge. By periodically rotating the PTFE film, a periodic potential difference was generated between the two $\mathrm{Cu}$ electrodes of the TENG, and such a potential difference was transformed into a direct current output signal by passing through a rectifier bridge. An external ammeter and voltmeter measured the electrical characteristics of the triboelectric plasma. The output voltage of the TENG (about $7.1 \mathrm{kV}$; Figure S2) was much greater than the threshold voltage of the $\mathrm{CO}$ mixture gas, which facilitated the discharge of the latter. For needle-plate distances $(d)$ of 3-11 mm, the TENG triggered the CO mixture gas discharge and generated the triboelectric corona plasma. When the $d$ value was less than $3 \mathrm{~mm}$, the corona discharge signal was transformed into multiple pulse discharge signals. The ${ }^{3} \mathrm{O}_{2}$ spin conversion during the triboelectric plasma process is depicted in Figure $2 \mathrm{~b}$. Free electrons near the tip of the $\mathrm{W}$ needle were accelerated in the electric field to 
form high-energy electrons [42-45], which then collided with the gas in the gap, generating the triboelectric plasma composed of a large number of electrons and positive ions via the avalanche effect. In the plasma region, some high-energy electrons were captured by the electronegative ${ }^{3} \mathrm{O}_{2}$ gas, and the ${ }^{3} \mathrm{O}_{2}$ molecules were transformed into reactive superoxide ions ${ }^{2} \mathrm{O}_{2}{ }^{-}$, which could overcome the spin prohibition to realize the $\mathrm{CO}$ oxidation reaction at room temperature.

a

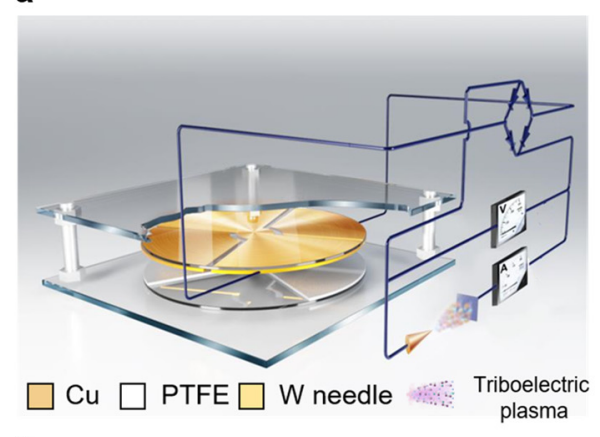

C

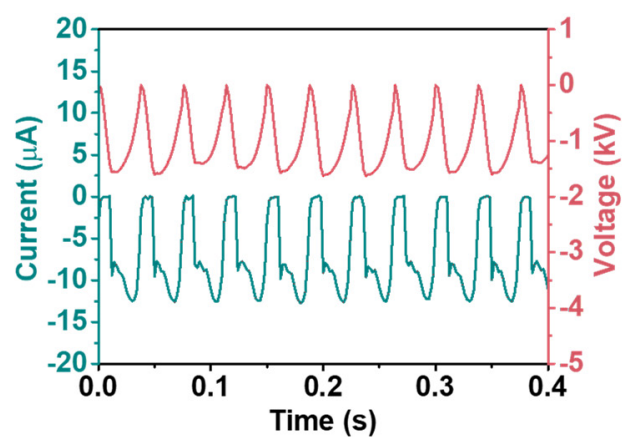

b
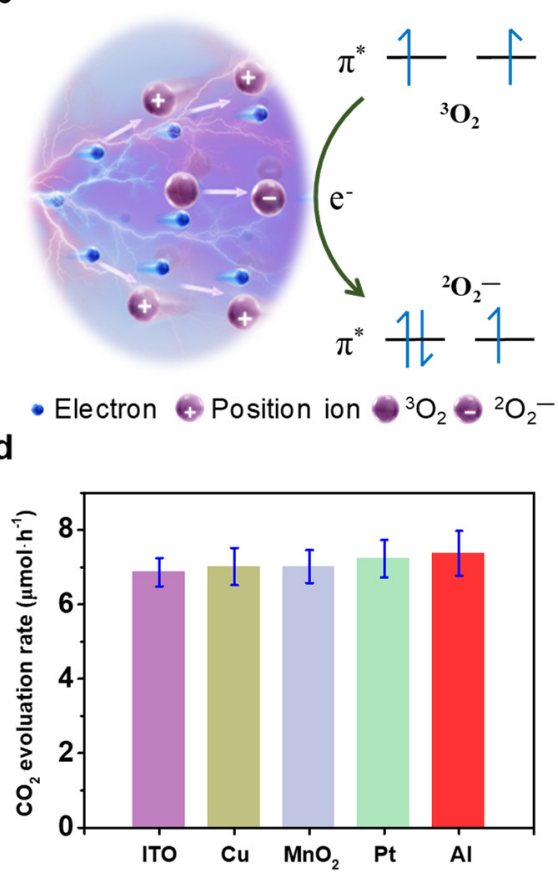

Figure 2. Schematic diagrams of the triboelectric plasma system. (a) Scheme of the triboelectric plasma oxidation system directly driven by a triboelectric nanogenerator (TENG). (b) ${ }^{3} \mathrm{O}_{2}$ spin conversion during the triboelectric plasma-induced process. (c) Electrical curves of the CO oxidation triggered by triboelectric plasma with a needle-plate distance of $3 \mathrm{~mm}$ using $\mathrm{Pt}$ as the electrode plate. (d) Activity for the triboelectric plasma-triggered $\mathrm{CO}$ oxidation with different electrode plate materials. Reaction conditions: negative corona, $3 \mathrm{~mm}$ needle-plate distance, $400 \mathrm{rpm}$ rotation speed, $\mathrm{CO} / \mathrm{O}_{2} / \mathrm{He}$ (1:20:79), $1 \mathrm{~h}$ discharge time, room temperature, and atmospheric pressure.

Figure 2c displays the electrical curve obtained for the $\mathrm{CO}$ oxidation system using triboelectric plasma generated by a TENG having a $d$ of $3 \mathrm{~mm}$. A pulse voltage peak of about $1.6 \mathrm{kV}$ accompanied by a discharge current peak of $12.5 \mu \mathrm{A}$ was generated in half a cycle. The time of the current pulse peak was $28 \mathrm{~ms}$, which corresponds to the generation of triboelectric corona plasma. Figure $2 \mathrm{~d}$ summarizes the $\mathrm{CO}$ oxidation activity of different electrode materials using the triboelectric plasma described in Figure 2c under normal temperature and pressure conditions. Almost all of the electrode materials showed a high $\mathrm{CO}$ oxidation activity of $6.9-7.4 \mu \mathrm{mol} \mathrm{h}^{-1}$. An ${ }^{18} \mathrm{O}$ isotope labeling experiment confirmed that ${ }^{3} \mathrm{O}_{2}$ participated in the $\mathrm{CO}$ oxidation reaction (Figure S3). These results indicate that the $\mathrm{CO}$ oxidation was mainly controlled by the triboelectric plasma, whereas the electrode materials had a minor effect on the $\mathrm{CO}$ oxidation activity. Thus, we selected $\mathrm{Pt}$ as the electrode for the following experiments due to its stable performance.

\subsection{Influence of Different Parameters on the CO Oxidation Activity}

The rotational speed of the TENG, the needle-plate distance, and the corona polarity affect the state of the triboelectric corona plasma and hence the activity of the oxidation reaction between ${ }^{2} \mathrm{O}_{2}{ }^{-}$and $\mathrm{CO}$. Taking negative corona as an example, we first investigated the effect of the rotational speed of the TENG on the CO oxidation activity, as shown 
in Figure S4. Upon increasing the rotational speed, the discharge voltage was almost maintained at $-1.6 \mathrm{kV}$, whereas the absolute value of the discharge current, the average power, and the $\mathrm{CO}$ oxidation activity increased from $2.9 \mu \mathrm{A}, 1.0 \mathrm{~mW}$, and $1.4 \mu \mathrm{mol} \mathrm{h}^{-1}$ to $14.7 \mu \mathrm{A}, 9.2 \mathrm{~mW}$, and $8.9 \mu \mathrm{mol} \mathrm{h}{ }^{-1}$, respectively. The energy consumption (EC) of the conversion of $1 \mathrm{~mol} \mathrm{CO}$ remained virtually unchanged at $4.2 \mathrm{MJ} \mathrm{mol}^{-1}$, indicating that the rotational speed has a weak effect on the EC of the $\mathrm{CO}$ oxidation reaction. Therefore, we selected $400 \mathrm{rpm}$ as the rotational speed of the TENG for the subsequent experiments.

Figure S5 shows the relationship between $d$ and the CO oxidation activity. As the $d$ value increased from 3 to $11 \mathrm{~mm}$, the absolute value of the discharge voltage increased from 1.6 to $3.9 \mathrm{kV}$, and the absolute value of the discharge current decreased from 12.5 to $5.7 \mu \mathrm{A}$. The average power decreased from 8.9 to $2.5 \mathrm{~mW}$, the activity dropped from 7.2 to $0.2 \mu \mathrm{mol} \mathrm{h}{ }^{-1}$, and the corresponding EC increased significantly from 4.2 to $45.4 \mathrm{MJ} \mathrm{mol}^{-1}$. According to these results, the optimal activity and minimum EC were achieved with a $d$ of $3 \mathrm{~mm}$, which we selected as the optimal needle-plate distance for the following experiments.

Then, we investigated the effect of the corona polarity on the CO oxidation activity, as shown in Figure 3 . When $d$ was $3 \mathrm{~mm}$, the absolute value of the discharge voltage of the negative corona $(1.6 \mathrm{kV})$ was lower than that of the positive corona $(3.2 \mathrm{kV})$, and the absolute value of the discharge current of the negative corona $(12.5 \mu \mathrm{A})$ was greater than that of the positive corona $(12.3 \mu \mathrm{A})$. The average power of the negative corona $(10.8 \mathrm{~mW})$ was lower than that of the positive corona $(8.9 \mathrm{~mW})$. The $\mathrm{CO}$ oxidation activity of the negative corona $(7.2 \mu \mathrm{mol} \mathrm{h}-1)$ was 2.7 times that of the positive corona $\left(2.8 \mu \mathrm{mol} \mathrm{h}^{-1}\right)$. Therefore, the calculated EC of the negative corona $\left(4.2 \mathrm{MJ} \mathrm{mol}^{-1}\right)$ was much lower than that of the positive corona $\left(14.6 \mathrm{MJ} \mathrm{mol}^{-1}\right)$. When $d$ was 5 or $7 \mathrm{~mm}$, the absolute value of discharge voltage and current and the activity trend were similar to those obtained with a $d$ of $3 \mathrm{~mm}$. The calculated average power of the negative corona was approximately equal for a $d$ of 3-7 mm, whereas that under the condition of positive corona decreased significantly with increasing the distance. Meanwhile, the trend of the EC at different polarities proved to be irrespective of the $d$ value. The above results imply that the negative corona afforded better activity and lower EC than the positive corona. Furthermore, we conducted cyclic experiments to evaluate the stability of the triboelectric plasma-triggered oxidation of $\mathrm{CO}$, finding that the system maintained its activity for five runs (Figure S6).

\subsection{Investigation of Dioxygen Activation by Triboelectric Plasma and Theoretical Calculations}

Subsequently, to gain insight into the reason for the EC difference for the CO oxidation reaction between the positive and negative corona, we performed a nitro blue tetrazolium (NBT) assay to detect the reactive species derived from ${ }^{3} \mathrm{O}_{2}$ in the triboelectric plasma by colorimetry [32], as shown in Figure 4a. Upon the reaction of $\mathrm{NBT}$ with ${ }^{2} \mathrm{O}_{2}{ }^{-}$, insoluble blue organic compounds were generated in the reaction solution, which caused a decrease in the absorbance of the solution at $260 \mathrm{~nm}$. In the absence of triboelectric plasma, the absorbance of the NBT solution decreased under $\mathrm{CO} / \mathrm{O}_{2} / \mathrm{He}$ atmosphere, suggesting the existence of ${ }^{2} \mathrm{O}_{2}{ }^{-}$radicals in the triboelectric plasma. Moreover, the absorption peak under the negative corona was lower than that under the positive corona, demonstrating that the former produced more ${ }^{2} \mathrm{O}_{2}{ }^{-}$radicals than the latter.

Next, we conducted kinetic isotope experiments under the same conditions using isotope-labeled and unlabeled ${ }^{3} \mathrm{O}_{2}$ to study the kinetics of the ${ }^{3} \mathrm{O}_{2}$ activation. Electrondriven reactions have been reported to show higher KIEs than thermally driven and light-driven reactions [46-48]. As shown in Figure $4 b$, we used the same ratio of $\mathrm{CO}$ mixed standard gas $\left(\mathrm{CO} /{ }^{16} \mathrm{O}_{2} / \mathrm{He}, \mathrm{CO} /{ }^{18} \mathrm{O}_{2} / \mathrm{He}\right)$ to evaluate the rate of $\mathrm{CO}$ oxidation reaction under the negative corona. The reaction rate was found to be $7.2 \mu \mathrm{mol} \mathrm{h}^{-1}$ under $\mathrm{CO} /{ }^{16} \mathrm{O}_{2} / \mathrm{He}$ atmosphere and $6.5 \mu \mathrm{mol} \mathrm{h}{ }^{-1}$ under $\mathrm{CO} /{ }^{18} \mathrm{O}_{2} / \mathrm{He}$ atmosphere. The KIE $\left({ }^{16} \mathrm{O}_{2}\right.$ rate $/{ }^{18} \mathrm{O}_{2}$ rate $)$ of the negative corona was $1.11 \pm 0.01$, which is larger than that reported for traditional thermal catalytic $\mathrm{CO}$ oxidation reactions (KIE =1.06) [46-48]. The larger KIE for the triboelectric plasma process is a typical feature of an electron-driven process and confirms that ${ }^{3} \mathrm{O}_{2}$ activation controls the entire reaction. 
a
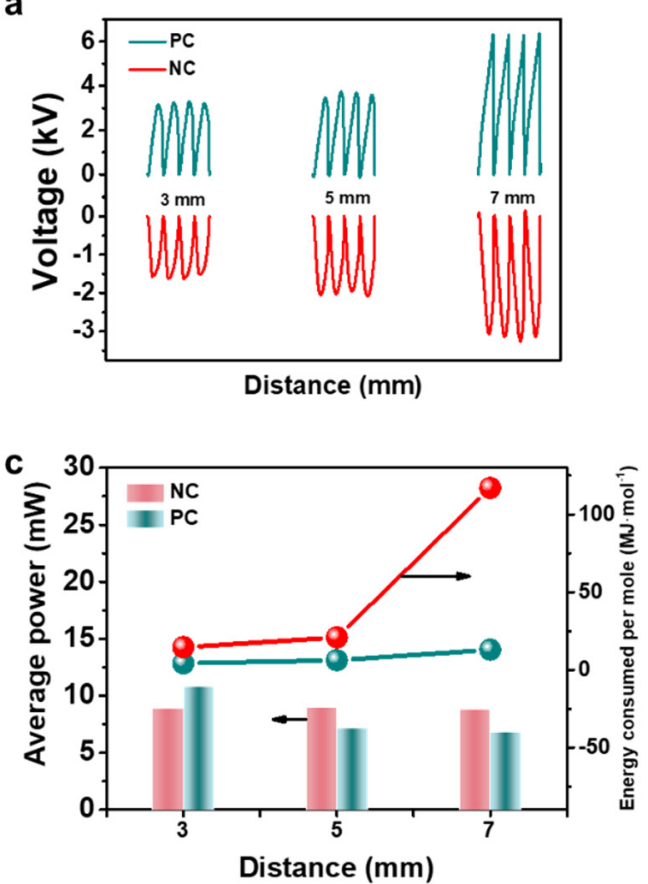

b
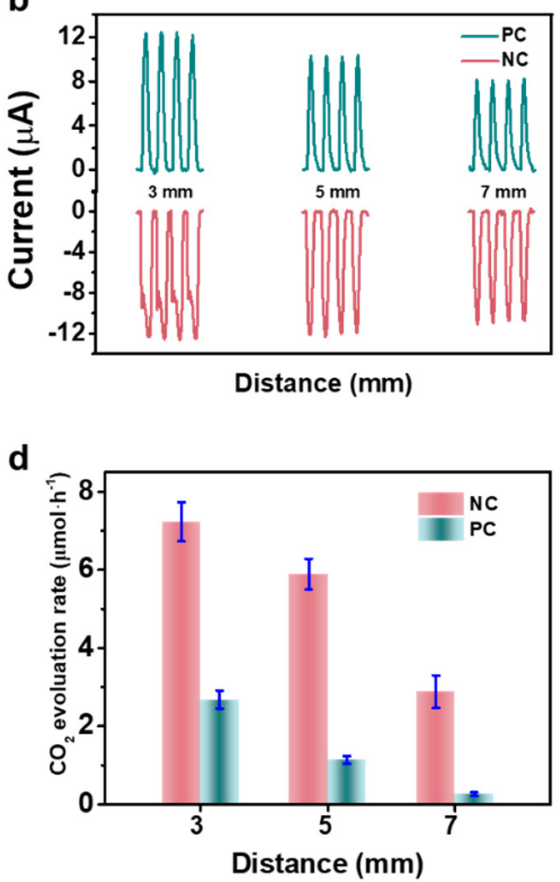

Figure 3. Activity dependence on the discharge polarities. (a) Voltage curves of different corona polarities; $\mathrm{NC}=$ negative corona. $\mathrm{PC}=$ positive corona. (b) Current curves of $\mathrm{CO}$ oxidation at different corona polarities. (c) Average power and energy consumption per mol CO at different corona polarities. (d) Activity of $\mathrm{CO}$ oxidation at different corona polarities. Reaction conditions: Pt as the electrode plate, $\mathrm{CO} / \mathrm{O}_{2} / \mathrm{He}(1: 20: 79), 1 \mathrm{~h}$ discharge time, room temperature, and atmospheric pressure.

a

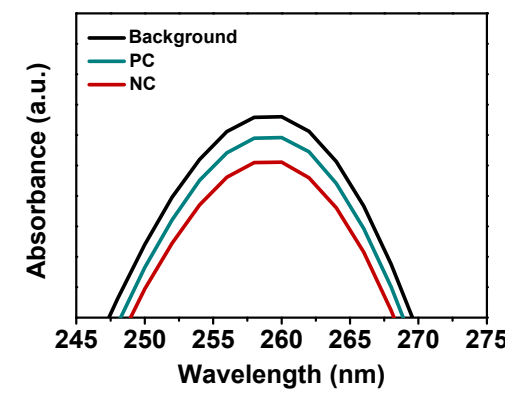

b

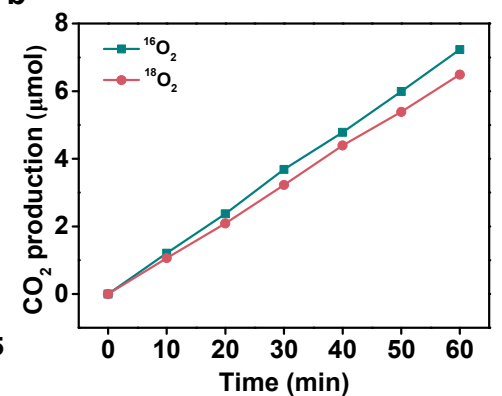

C

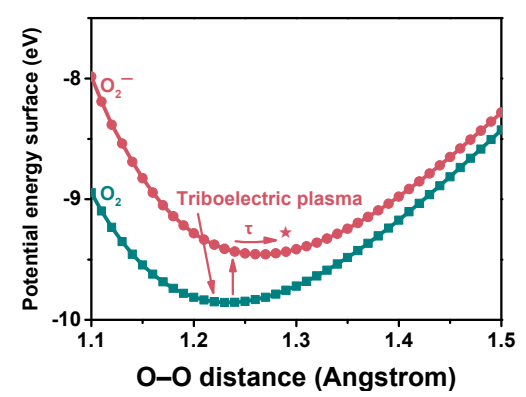

Figure 4. Activation of ${ }^{3} \mathrm{O}_{2}$. (a) Reactive oxygen generated from ${ }^{3} \mathrm{O}_{2}$ measured by colorimetry using a nitro blue tetrazolium solution; a.u. = arbitrary units. (b) Reaction rate for the triboelectric plasma-triggered CO oxidation measured at room temperature for ${ }^{16} \mathrm{O}_{2}$ and ${ }^{18} \mathrm{O}_{2}$ reactants. Reaction conditions: negative corona, $3 \mathrm{~mm}$ needle-plate distance, $400 \mathrm{rpm}$ rotation speed, $\mathrm{Pt}$ as the electrode plate, $\mathrm{CO} / \mathrm{O}_{2} / \mathrm{He}$ (1:20:79), $1 \mathrm{~h}$ discharge time, room temperature, and atmospheric pressure. (c) Density functional theory-calculated ${ }^{3} \mathrm{O}_{2}$ and ${ }^{2} \mathrm{O}_{2}{ }^{-}$potential energy surface. Excitation of triboelectric plasma allows the high-energetic electrons to be transferred to ${ }^{3} \mathrm{O}_{2}$, generating ${ }^{2} \mathrm{O}_{2}{ }^{-}$. The ${ }^{3} \mathrm{O}_{2}$ molecule is negatively charged, and the $\mathrm{O}-\mathrm{O}$ nuclear motion relaxes to an equilibrium state along the ${ }^{2} \mathrm{O}_{2}{ }^{-}$potential energy surface. $\star=$ equilibrium state. $\tau$ denotes the progression of ${ }^{2} \mathrm{O}_{2}{ }^{-}$along the ${ }^{2} \mathrm{O}_{2}{ }^{-}$potential energy surface as a function of time.

The larger KIE indicates that high-energy electrons promote the overall reaction via an electron-induced activation of ${ }^{3} \mathrm{O}_{2}$. Combined with the presence of ${ }^{3} \mathrm{O}_{2}$-derived reactive species as revealed by the colorimetry analysis, in the context of the reactions herein reported, we speculated that an energetic electron was directly transferred to the $\pi^{*}$ antibonding orbital (i.e., LUMO energy level) of molecular ${ }^{3} \mathrm{O}_{2}$, resulting in the production of ${ }^{2} \mathrm{O}_{2}{ }^{-}$, which effectively promoted the spin change and activation of ${ }^{3} \mathrm{O}_{2}$. To further study the electron transfer process from the triboelectric plasma to ${ }^{3} \mathrm{O}_{2}$ molecules, we determined 
the potential energy surfaces of ${ }^{3} \mathrm{O}_{2}$ and ${ }^{2} \mathrm{O}_{2}{ }^{-}$(Figure 4c) by performing DFT and a linear expansion delta self-consistent field extension of DFT $(\triangle \mathrm{SCF}-\mathrm{DFT})$, respectively. Figure $4 \mathrm{c}$ shows that the minimum energy required for populating the antibonding orbital of the ${ }^{3} \mathrm{O}_{2}$ molecule was $0.5 \mathrm{eV}$, which corresponds to the vertical transition energy between the potential energy surface of ${ }^{2} \mathrm{O}_{2}{ }^{-}$and the ground state ${ }^{3} \mathrm{O}_{2}$. Upon transferring an electron to the antibonding orbital of the ${ }^{2} \mathrm{O}_{2}$ molecule, the $\mathrm{O}-\mathrm{O}$ bond (the $\mathrm{O}-\mathrm{O}$ bond length in $\mathrm{O}_{2}$ is $1.23 \AA$ ) underwent a stretching process: namely, the lowest potential energy configuration for the negatively charged ${ }^{2} \mathrm{O}_{2}{ }^{-}$ions exhibited a longer $\mathrm{O}-\mathrm{O}$ bond of $1.32 \AA$ [49].

\subsection{Theoretical Simulation of Triboelectric Plasma}

Figure $5 \mathrm{a}, \mathrm{b}$ show the simulated time evolution of the electron density and the electron average energy under the negative corona with a $d$ of $3 \mathrm{~mm}$. As the time increased from 0.5 to $4.5 \mathrm{~ns}$, electrons migrated from the tip of the $\mathrm{W}$ needle to the plate electrode, generating a plasma channel of a cylinder with a radius of $1.5 \mathrm{~mm}$. The electron density was evenly distributed in the whole plasma channel, and the electron densities near the tip (point i), the middle (point ii), and the plate electrode (point iii) were $1.4 \times 10^{19}, 1.97 \times 10^{19}$, and $4.9 \times 10^{19} \mathrm{~m}^{-3}$, respectively. The average energy of electrons was evenly distributed in the whole plasma. The average energy of electrons near the tip (point i), the middle (point ii), and the plate electrode (point iii) were 3.6, 5.4, and $4.4 \mathrm{eV}$, respectively. The lower energy of electrons near the tip was mainly caused by the electric field shielding effect of the plasma.

Figure $5 \mathrm{c}, \mathrm{d}$ show the simulated time evolution of the electron density and the electron average energy for the positive corona. Upon increasing the time, electrons migrated from the tip of the $\mathrm{W}$ needle to the plate electrode, forming a core with a radius of $1.0 \mathrm{~mm}$. The electron density near the needle tip (point i) and near the plate electrode (point iii) was $1.2 \times 10^{18}$ and $2.4 \times 10^{15} \mathrm{~m}^{-3}$, respectively. The average energy of electrons was relatively high (about $9.5 \mathrm{eV}$ ) at the plasma head (point ii) and relatively low (about $0.75 \mathrm{eV}$ ) at the tail (point i), which was caused by the electric field shielding effect generated by the plasma.

The normalized electron energy distribution function of the three representative points (i, ii, and iii) is shown in Figure 5e. The distance between the needle tip and the three representative points was $0.6,1.8$, and $2.6 \mathrm{~mm}$, respectively. The average energy of electrons at point $i$ was lower than that at points ii and iii. For example, in point $i$, the energy of $100 \%$ electrons at the positive corona and $86 \%$ electrons at the negative corona was less than $5 \mathrm{eV}$. At points ii and iii, the energy of $61 \%$ electrons at the positive corona and $74 \%$ electrons at the negative corona was less than $5 \mathrm{eV}$, respectively. The energy of $73 \%$ electrons at the positive corona and $77 \%$ electrons at the negative corona was less than $5 \mathrm{eV}$. At point iii, the electron density of the positive corona was about four orders of magnitude smaller than that of the negative corona.

\subsection{Mechanism of the Triboelectric Plasma-Triggered CO Oxidation}

Figure 6 depicts two plausible mechanisms for the $\mathrm{CO}$ oxidation triggered by triboelectric plasma: pathways a and $b$. In pathway a, the formation of ${ }^{2} \mathrm{O}_{2}{ }^{-}$ions by changing the spin state of ${ }^{3} \mathrm{O}_{2}$ allows overcoming the spin-forbidden nature of the reaction between ${ }^{3} \mathrm{O}_{2}$ and CO, resulting in a low-energy barrier. This pathway includes three steps: (1) ${ }^{3} \mathrm{O}_{2}$ captures low-energy electrons to form ${ }^{2} \mathrm{O}_{2}{ }^{-}$ions with a potential barrier of $0.5 \mathrm{eV} ;(2){ }^{2} \mathrm{O}_{2}{ }^{-}$ ions react with $\mathrm{CO}$ to form $\mathrm{CO}$ and $\mathrm{O}^{-}$ion, and the energy barrier is $1.35 \mathrm{eV} \mathrm{[50];} \mathrm{(3)} \mathrm{O}^{-}$reacts with $\mathrm{CO}$ to produce $\mathrm{CO}_{2}$ and $\mathrm{e}^{-}$with an energy barrier of $-4 \mathrm{eV}$. Pathway b comprises the direct reaction between ${ }^{3} \mathrm{O}_{2}$ and $\mathrm{CO}$ under the action of high-energy electrons, which proceeds through a high-energy triplet transition state. This process does not overcome the spin prohibition of the reaction between ${ }^{3} \mathrm{O}_{2}$ and $\mathrm{CO}$; therefore, the energy barrier is high. This pathway includes two reaction processes: (1) under the action of high-energy electrons, ${ }^{3} \mathrm{O}_{2}$ reacts directly with $\mathrm{CO}$ to produce $\mathrm{CO}_{2}$ and $\mathrm{O}$ atom, and the energy barrier is $5.2 \mathrm{eV}$; (2) The dioxygen atom reacts with $\mathrm{CO}$ to produce $\mathrm{CO}_{2}$ with an energy barrier of $-5.5 \mathrm{eV}$. The total energy barrier calculated for pathway a and pathway $\mathrm{b}$ was 1.85 
and $5.2 \mathrm{eV}$, respectively. Therefore, pathway a is thermodynamically more favored than pathway b.
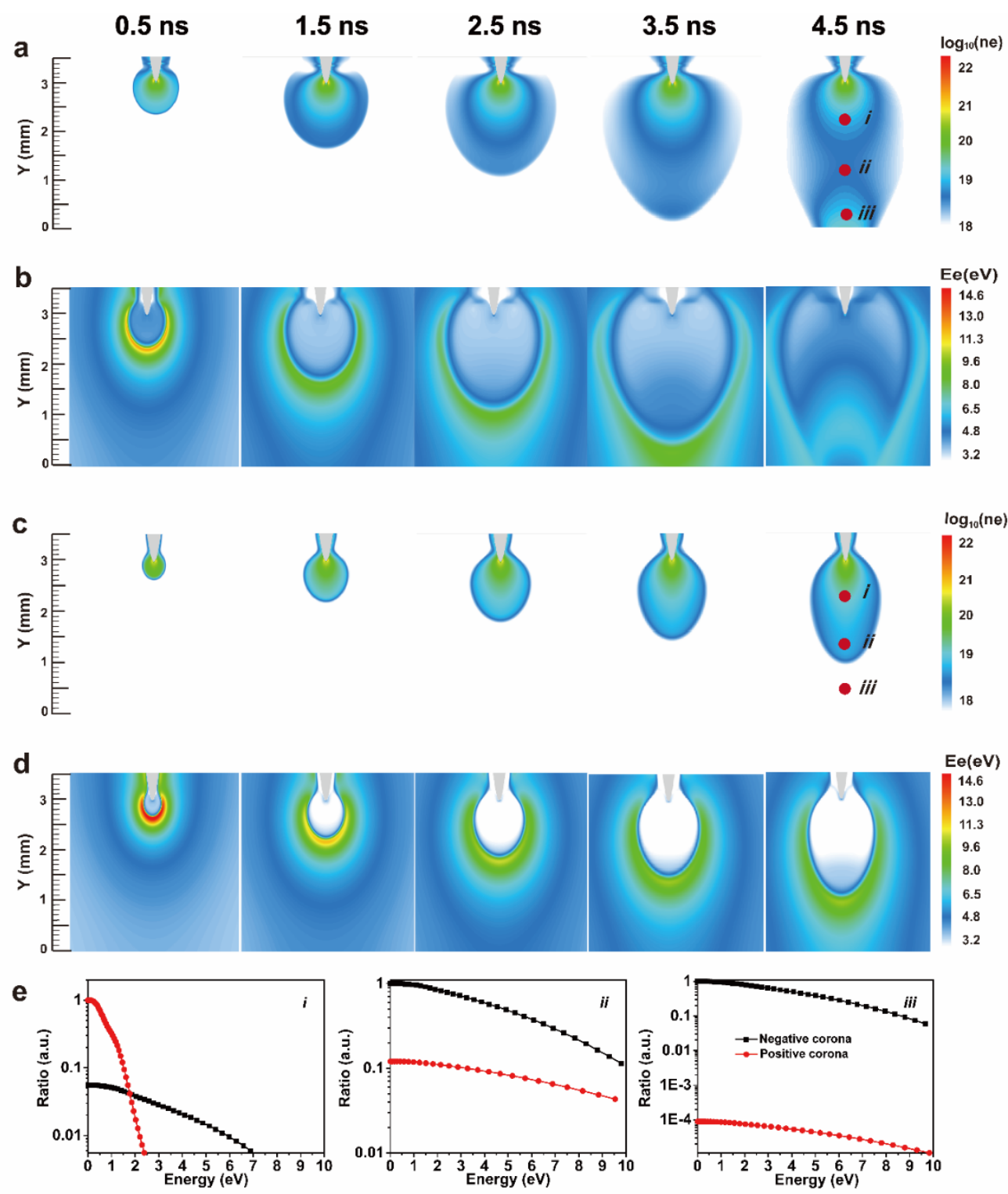

Figure 5. Triboelectric plasma simulation. (a) Time evolution of the electron density distribution in the negative corona. (b) Time evolution of the electron energy distribution in the negative corona. (c) Time evolution of the electron density distribution in the positive corona. (d) Time evolution of the electron energy distribution in the positive corona. (e) Electron energy distribution function of three representative points ( $\mathrm{i}$, ii, iii) both in the negative and the positive corona. 
Pathway a

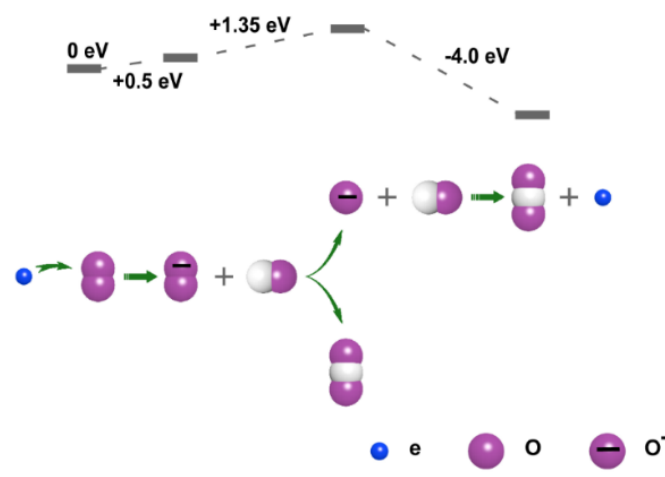

Pathway b

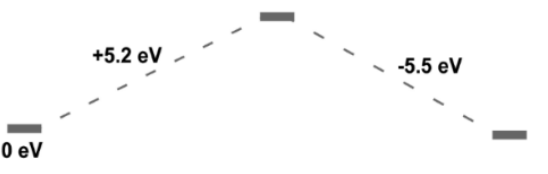

$:+$

$\bullet+$

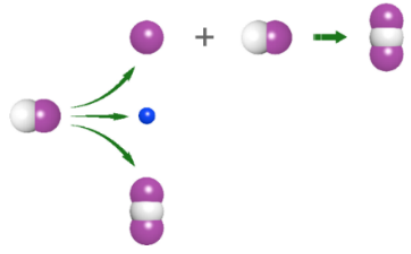

Figure 6. Reaction pathways for triboelectric plasma-triggered CO oxidation.

In the process of the negative corona, the average energy and average density of electrons were evenly distributed in the whole plasma channel. Except for the plasma head (near the plate electrode), the average energy of other electrons was less than $5 \mathrm{eV}$, and the energy was not sufficient for the process to proceed through pathway $b$, as shown in Figure 7. Therefore, in the whole plasma at the negative corona, pathway a occurs in almost all regions, whereas the process only proceeds through pathway $b$ in the plasma head (plate electrode position). In the positive corona process, two obvious regions were formed in the plasma channel: a low-energy electron region near the needle tip and a high-energy electron region at the front edge of the plasma. The energy of electrons near the needle tip was very low; although it could produce highly active ${ }^{2} \mathrm{O}_{2}{ }^{-}$ions, it was not sufficient to promote ${ }^{2} \mathrm{O}_{2}{ }^{-}$decomposition. In the front of the plasma, $49 \%$ of the electrons have an energy greater than $5 \mathrm{eV}$, which is sufficient to overcome the energy barrier of pathway $b$. Therefore, in the positive corona, the oxidation of CO mainly occurred through pathways a and b. Finally, the proportion of pathway a in the negative corona was greater than that in the positive corona; therefore, the energy efficiency and activity of the negative corona were higher than those of the positive corona.

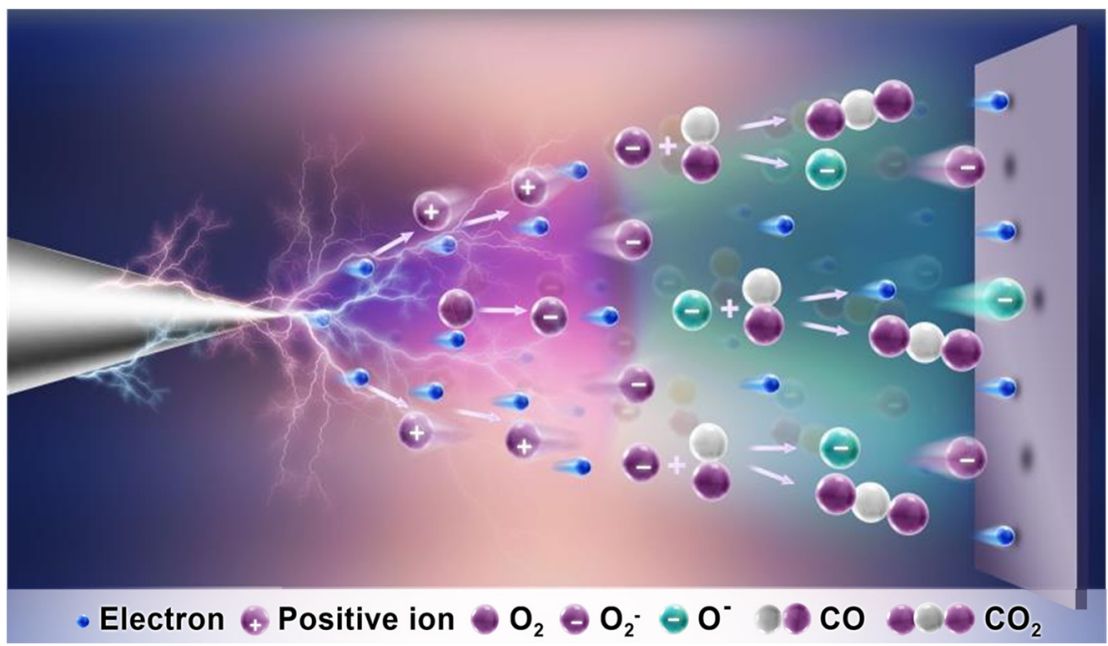

Figure 7. Schematic diagram of triboelectric plasma-triggered $\mathrm{CO}$ oxidation reaction at negative corona.

In the $\mathrm{CO}$ oxidation reaction, the activation of ${ }^{3} \mathrm{O}_{2}$ has always been considered as the key step [51]. At room temperature, since the ${ }^{3} \mathrm{O}_{2}$ molecule is in the triplet state, the oxidation needs to proceed through a high-energy triplet transition state to satisfy the spin 
selection rules. Therefore, although the ${ }^{3} \mathrm{O}_{2}$ molecule has a strong oxidizing ability, the direct oxidation of $\mathrm{CO}$ is unfavorable in terms of reaction kinetics. This is the so-called spin conservation process. In thermally induced catalytic systems, the electrons of the $d$ orbital of a transition metal are transferred to the antibonding orbital of ${ }^{3} \mathrm{O}_{2}$ (Table S1). Meanwhile, in photocatalytic systems, after the photogenerated carriers are separated on the photocatalyst, the electrons trapped on the reduction cocatalyst migrate to the antibonding orbital of the ${ }^{3} \mathrm{O}_{2}$ molecule. The ${ }^{3} \mathrm{O}_{2}$ single electron transfer to form ${ }^{2} \mathrm{O}_{2}{ }^{-}$ at room temperature has been reported to require metal or metal oxide catalysts. In our system, the triboelectric corona plasma contains a large number of high-energy electrons that can be directly injected into the antibonding orbital of ${ }^{3} \mathrm{O}_{2}$ to produce highly active ${ }^{2} \mathrm{O}_{2}{ }^{-}$, enabling the $\mathrm{CO}$ oxidation reaction. This system can directly realize the single electron transfer to form a ${ }^{2} \mathrm{O}_{2}{ }^{-}$free radical in the absence of a metal catalyst, which offers the advantages of low cost and no noble metal pollution [52]. The reaction device is simple and easy to operate, and the driving force of the reaction mainly comes from renewable and green mechanical energy.

\section{Conclusions}

We have developed a method that used the triboelectric corona plasma generated by a TENG under mechanical stimuli to change the spin state of $\mathrm{O}_{2}$ molecules and trigger the $\mathrm{CO}$ oxidation reaction at room temperature. The rotation speed of the TENG, the needle-plate distance, and the corona polarity have an important influence on the $\mathrm{CO}$ oxidation reaction. Under a rotation speed of $400 \mathrm{rpm}$, a needle-plate distance of $3 \mathrm{~mm}$, and negative corona, the optimal activity was $7.2 \mu \mathrm{mol} \mathrm{h}^{-1}$ and the lowest energy consumption per mole CO was $4.2 \mathrm{MJ}$. The high-energy electrons in the triboelectric corona plasma were directly injected into the antibonding orbitals of $\mathrm{O}_{2}$ to form highly reactive $\mathrm{O}_{2}{ }^{-}$radicals. The energy barrier of the reaction of the excited $\mathrm{O}_{2}{ }^{-}$ions with $\mathrm{CO}$ is $3.4 \mathrm{eV}$ lower than that of the $\mathrm{O}_{2}$ reaction, effectively promoting the rate-limiting step of $\mathrm{O}-\mathrm{O}$ bond dissociation in the $\mathrm{CO}$ oxidation reaction. This work provides a novel strategy that circumvents the spin-forbidden nature of the activation of small molecules through mechanical energy.

Supplementary Materials: The following are available online at https: / www.mdpi.com/article / 10.3390/nano11123408/s1, Figure S1: Diagram of triboelectric plasma oxidation of CO, Figure S2: Electric curves, Figure S3: Isotope experiment, Figure S4: The effect of different rotational speeds of TENG, Figure S5: The effect of different needle-plate distances, Figure S6: Cycle experiment, Table S1: Comparison of different methods of oxidation of $\mathrm{CO}$.

Author Contributions: Conceptualization, X.S., B.Z. and S.L.; methodology, B.Z., X.X., Y.Z. and G.C.; formal analysis, X.S., S.L., X.X., Y.Z. and K.Z.; validation, J.W., K.Z., W.S. and G.G.; investigation, J.G. and P.C.; funding acquisition, B.Z., G.G., P.C., G.C. and Z.D.; supervision, G.C. and Z.D.; writing—original draft, B.Z.; writing—review and editing, G.C. and Z.D. All authors have read and agreed to the published version of the manuscript.

Funding: This research was funded by the National Natural Science Foundation of China, grant number 21902043, 61974040, 22005086, and 62104064; Chinese Postdoctoral Science Foundation, grant number 2020M672197; Postdoctoral Foundation of Henan Province, China, grant number 248472; Key Research \& Development and Promotion Project of Henan Province, China, grant number 212102311004.

Institutional Review Board Statement: Not applicable.

Informed Consent Statement: Not applicable.

Data Availability Statement: The data are available upon reasonable request from the corresponding author.

Conflicts of Interest: The authors declare no conflict of interest. 


\section{References}

1. Behler, J.; Delley, B.; Lorenz, S.; Reuter, K.; Scheffler, M. Dissociation of $\mathrm{O}_{2}$ at $\mathrm{Al}(111)$ : The role of spin selection rules. Phys. Rev. Lett. 2005, 94, 036104. [CrossRef] [PubMed]

2. Shen, X.M.; Liu, W.Q.; Gao, X.J.; Lu, Z.H.; Wu, X.C.; Gao, X.F. Mechanisms of oxidase and superoxide dismutation-like activities of gold, silver, platinum, and palladium, and their alloys: A general way to the activation of molecular oxygen. J. Am. Chem. Soc. 2015, 137, 15882-15891. [CrossRef] [PubMed]

3. Chen, Y.-Z.; Wang, Z.Y.U.; Wang, H.W.; Lu, J.L.; Yu, S.-H.; Jiang, H.-L. Singlet oxygen-engaged selective photo-oxidation over Pt nanocrystals/porphyrinic MOF: The roles of photothermal effect and Pt electronic state. J. Am. Chem. Soc. 2017, 139, 2035-2044. [CrossRef] [PubMed]

4. Sun, X.S.; Luo, X.; Zhang, X.D.; Xie, J.F.; Jin, S.; Wang, H.; Zheng, X.S.; Wu, X.J.; Xie, Y. Enhanced superoxide generation on defective surfaces for selective photooxidation. J. Am. Chem. Soc. 2019, 141, 3797-3801. [CrossRef]

5. Zhang, N.; Li, X.Y.; Ye, H.C.; Chen, S.M.; Ju, H.X.; Liu, D.B.; Lin, Y.; Ye, W.; Wang, C.M.; Xu, Q.; et al. Oxide defect engineering enables to couple solar energy into oxygen activation. J. Am. Chem. Soc. 2016, 138, 8928-8935. [CrossRef]

6. Zhang, B.; Yang, X.J.; Li, J.; Cheng, G. Selective aerobic oxidation of alkyl aromatics on $\mathrm{Bi}_{2} \mathrm{MoO}_{6}$ nanoplates decorated with Pt nanoparticles under visible light irradiation. Chem. Commun. 2018, 54, 12194-12197. [CrossRef]

7. Zhang, B.; Li, J.; Gao, Y.Y.; Chong, R.F.; Wang, Z.L.; Guo, L.; Zhang, X.W.; Li, C. To boost photocatalytic activity in selective oxidation of alcohols on ultrathin $\mathrm{Bi}_{2} \mathrm{MoO}_{6}$ nanoplates with Pt nanoparticles as cocatalyst. J. Catal. 2017, 345, 96-103. [CrossRef]

8. Zhang, B.; Li, J.; Zhang, B.Q.; Chong, R.F.; Li, R.G.; Yuan, B.; Lu, S.-M.; Li, C. Selective oxidation of sulfides on Pt/BiVO 4 photocatalyst under visible light irradiation using water as the oxygen source and dioxygen as the electron acceptor. J. Catal. 2015, 332, 95-100. [CrossRef]

9. Long, R.; Mao, K.K.; Gong, M.; Zhou, S.; Hu, J.H.; Zhi, M.; You, Y.; Bai, S.; Jiang, J.; Zhang, Q.; et al. Tunable oxygen activation for catalytic organic oxidation: Schottky junction versus plasmonic effects. Angew. Chem. Int. Ed. 2014, 53, 3205-3209. [CrossRef]

10. Zhang, B.; Li, J.; Guo, L.; Chen, Z.P.; Li, C. Photothermally promoted cleavage of beta-1,4-glycosidic bonds of cellulosic biomass on Ir/HY catalyst under mild conditions. Appl. Catal. B 2018, 237, 660-664. [CrossRef]

11. Hori, H.; Takashima, M.; Takase, M.; Ohtani, B. Kinetic analysis supporting multielectron reduction of oxygen in bismuth tungstate-photocatalyzed oxidation of organic compounds. Catal. Today 2018, 313, 218-223. [CrossRef]

12. Setvín, M.; Aschauer, U.; Scheiber, P.; Li, Y.-F.; Hou, W.Y.; Schmid, M.; Selloni, A.; Diebold, U. Reaction of $\mathrm{O}_{2}$ with subsurface oxygen vacancies on $\mathrm{TiO}_{2}$ anatase (101). Science 2013, 341, 988-991. [CrossRef]

13. Su, H.; Zhang, K.-X.; Zhang, B.; Wang, H.-H.; Yu, Q.Y.; Li, X.-H.; Antonietti, M.; Chen, J.S. Activating cobalt nanoparticles via the Mott-Schottky effect in nitrogen-rich carbon shells for base-free aerobic oxidation of alcohols to esters. J. Am. Chem. Soc. 2017, 139, 811-818. [CrossRef]

14. Jagadeesh, R.V.; Junge, H.; Pohl, M.M.; Radnik, J.; Bruckner, A.; Beller, M. Selective oxidation of alcohols to esters using heterogeneous $\mathrm{Co}_{3} \mathrm{O}_{4}-\mathrm{N} @ \mathrm{C}$ catalysts under mild conditions. J. Am. Chem. Soc. 2013, 135, 10776-10782. [CrossRef]

15. Wu, W.T.; Zhang, Q.G.; Wang, X.K.; Han, C.C.; Shao, X.D.; Wang, Y.X.; Liu, J.L.; Li, Z.T.; Lu, X.Q.; Wu, M.B. Enhancing selective photooxidation through Co-Nx-doped carbon materials as singlet oxygen photosensitizers. ACS Catal. 2017, 7, 7267-7273. [CrossRef]

16. Leung, S.-F.; Fu, H.-C.; Zhang, M.L.; Hassan, A.H.; Jiang, T.; Salama, K.N.; Wang, Z.L.; He, J.-H. Blue energy fuels: Converting ocean wave energy to carbon-based liquid fuels via $\mathrm{CO}_{2}$ reduction. Energy Environ. Sci. 2020, 13, 1300-1308. [CrossRef]

17. You, H.L.; Wu, Z.; Zhang, L.H.; Ying, Y.R.; Liu, Y.; Fei, L.F.; Chen, X.X.; Jia, Y.M.; Wang, Y.J.; Wang, F.F.; et al. Harvesting the vibration energy of $\mathrm{BiFeO}_{3}$ nanosheets for hydrogen evolution. Angew. Chem. Int. Ed. 2019, 58, 11779-11784. [CrossRef]

18. Gao, S.Y.; Zhu, Y.Z.; Chen, Y.; Tian, M.; Yang, Y.J.; Jiang, T.; Wang, Z.L. Self-power electroreduction of $\mathrm{N}_{2}$ into $\mathrm{NH}_{3}$ by $3 \mathrm{D}$ printed triboelectric nanogenerators. Mater. Today 2019, 28, 17-24. [CrossRef]

19. Fan, F.R.; Tian, Z.Q.; Wang, Z.L. Flexible triboelectric generator! Nano Energy 2012, 1, 328-334. [CrossRef]

20. Sahu, M.Š.; Silvija, H.S.; Padhan, A.M.; Živković, P.; Jokić, S.; Kim, H.J. Development of triboelectric nanogenerator and mechanical energy harvesting using argon ion-implanted kapton, zinc oxide and kapton. Mater. Lett. 2021, 301, 130290. [CrossRef]

21. Seo, J.H.; Sugato, S.; Manisha, K.; Hoe, J. Effect of cilia microstructure and ion injection upon single-electrode triboelectric nanogenerator for effective energy harvesting. Mater. Lett. 2021, 304, 130674. [CrossRef]

22. Venugopal, K.; Panchatcharam, P.; Chandrasekhar, A.; Shanmugasundaram, V. Comprehensive review on triboelectric nanogenerator based wrist pulse measurement: Sensor fabrication and diagnosis of arterial pressure. ACS Sens. 2021, 6, 1681-1694. [CrossRef]

23. Chandrasekhar, A.; Vivekananthan, V.; Khandelwal, G.; Kim, W.J.; Kim, S.J. Green energy from working surfaces: A contact electrification-enabled data theft protection and monitoring smart table. Mater. Today Energy 2020, 18, 100544. [CrossRef]

24. Feng, Y.W.; Ling, L.L.; Nie, J.; Han, K.; Chen, X.Y.; Bian, Z.F.; Li, H.X.; Wang, Z.L. Self-powered electrostatic filter with enhanced photocatalytic degradation of formaldehyde based on built-in triboelectric nanogenerators. ACS Nano 2017, 11, 12411-12418. [CrossRef]

25. Gao, S.Y.; Su, J.Z.; Wei, X.J.; Wang, M.; Tian, M.; Jiang, T.; Wang, Z.L. Self-powered electrochemical oxidation of 4-aminoazobenzene driven by a triboelectric nanogenerator. ACS Nano 2017, 11, 770-778. [CrossRef] 
26. Cheng, G.; Zheng, H.W.; Yang, F.; Zhao, L.; Zheng, M.L.; Yang, J.J.; Qin, H.F.; Du, Z.L.; Wang, Z.L. Managing and maximizing the output power of a triboelectric nanogenerator by controlled tip-electrode air-discharging and application for UV sensing. Nano Energy 2018, 44, 208-216. [CrossRef]

27. Zhao, K.; Gu, G.Q.; Zhang, Y.N.; Zhang, B.; Yang, F.; Zhao, L.; Zheng, M.L.; Cheng, G.; Du, Z.L. The self-powered CO 2 gas sensor based on gas discharge induced by triboelectric nanogenerator. Nano Energy 2018, 53, 898-905. [CrossRef]

28. Li, A.Y.; Zi, Y.L.; Guo, H.Y.; Wang, Z.L.; Fernandez, F.M. Triboelectric nanogenerators for sensitive nano-coulomb molecular mass spectrometry. Nat. Nanotechnol. 2017, 12, 481-487. [CrossRef]

29. Han, K.; Luo, J.J.; Feng, Y.W.; Lai, Q.S.; Bai, Y.; Tang, W.; Wang, Z.L. Wind-driven radial-engine-shaped triboelectric nanogenerators for self-powered absorption and degradation of NOX. ACS Nano 2020, 14, 2751-2759. [CrossRef]

30. Cheng, J.; Ding, W.B.; Zi, Y.L.; Lu, Y.J.; Ji, L.J.; Liu, F.; Wu, C.S.; Wang, Z.L. Triboelectric microplasma powered by mechanical stimuli. Nat. Commun. 2018, 9, 3733. [CrossRef]

31. Wong, M.-C.; Xu, W.; Hao, J.H. Microplasma-discharge-based nitrogen fixation driven by triboelectric nanogenerator toward self-powered mechano-nitrogenous fertilizer supplier. Adv. Funct. Mater. 2019, 29, 1904090. [CrossRef]

32. Goto, H.; Hanada, Y.; Ohno, T.; Matsumura, M. Quantitative analysis of superoxide ion and hydrogen peroxide produced from molecular oxygen on photoirradiated $\mathrm{TiO}_{2}$ particles. J. Catal. 2004, 225, 223-229. [CrossRef]

33. Kresse, G.; Furthmüller, J. Efficient iterative schemes for ab initio total-energy calculations using a plane-wave basis set. Phys. Rev. B 1996, 54, 11169-11186. [CrossRef] [PubMed]

34. Kresse, G.; Hafner, J. Ab initio molecular-dynamics simulation of the liquid-metal-amorphous-semiconductor transition in germanium. Phys. Rev. B 1994, 49, 14251-14269. [CrossRef]

35. Blochl, P.E. Projector augmented-wave method. Phys. Rev. B 1994, 50, 17953-17979. [CrossRef]

36. Perdew, J.P.; Burke, K.; Ernzerhof, M. Generalized gradient approximation made simple. Phys. Rev. Lett. 1996, 77, 3865-3868. [CrossRef]

37. Zhu, Y.F.; Shcherbanev, S.; Baron, B.; Starikovskaia, S. Nanosecond surface dielectric barrier discharge in atmospheric pressure air: I. measurements and 2D modeling of morphology, propagation and hydrodynamic perturbations. Plasma Sources Sci. Technol. 2017, 26, 125004. [CrossRef]

38. Zhu, Y.F.; Starikovskaia, S. Fast gas heating of nanosecond pulsed surface dielectric barrier discharge: Spatial distribution and fractional contribution from kinetics. Plasma Sources Sci. Technol. 2018, 27, 124007. [CrossRef]

39. Zhu, Y.F.; Wu, Y.; Wei, B.; Xu, H.J.; Liang, H.; Jia, M.; Song, H.M.; Li, Y.H. Nanosecond-pulsed dielectric barrier discharge-based plasma-assisted anti-icing: Modeling and mechanism analysis. J. Phys. D Appl. Phys. 2019, 53, 145205. [CrossRef]

40. Kulikovsky, A.A. Positive streamer in a weak field in air: A moving avalanche-to-streamer transition. Phys. Rev. E 1997, 57, 7066-7074. [CrossRef]

41. Flitti, A.; Pancheshnyi, S. Gas heating in fast pulsed discharges in $\mathrm{N}_{2}-\mathrm{O}_{2}$ mixtures. Phys. J. Appl. Phys. 2009, 45, 21001. [CrossRef]

42. Bogaerts, A.; Neyts, E.C. Plasma technology: An emerging technology for energy storage. ACS Energy Lett. 2018, 3, $1013-1027$. [CrossRef]

43. Mehta, P.; Barboun, P.; Go, D.B.; Hicks, J.C.; Schneider, W.F. Catalysis enabled by plasma activation of strong chemical bonds: A review. ACS Energy Lett. 2019, 4, 1115-1133. [CrossRef]

44. Mehta, P.; Barboun, P.; Herrera, F.A.; Kim, J.; Rumbach, P.; Go, D.B.; Hicks, J.C.; Schneider, W.F. Overcoming ammonia synthesis scaling relations with plasma-enabled catalysis. Nat. Catal. 2018, 1, 269-275. [CrossRef]

45. Chen, J.H.; Davidson, J.H. Model of the negative DC corona plasma comparison to the positive DC corona plasma. Plasma Chem. Plasma Process. 2003, 23, 83-102. [CrossRef]

46. Denzler, D.N.; Frischkorn, C.; Hess, C.; Wolf, M.; Ertl, G. Electronic excitation and dynamic promotion of a surface reaction. Phys. Rev. Lett. 2003, 91, 226102. [CrossRef]

47. Funk, S.; Bonn, M.; Denzler, D.N.; Hess, C.; Wolf, M.; Ertl, G. Desorption of CO from Ru(001) induced by near-infrared femtosecond laser pulses. J. Chem. Phys. 2000, 112, 9888-9897. [CrossRef]

48. Bonn, M.; Funk, S.; Hess, C.; Denzler, D.N.; Stampfl, C.; Scheffler, M.; Wolf, M.; Ertl, C. Phonon-versus electron-mediated desorption and oxidation of $\mathrm{CO}$ on $\mathrm{Ru}(0001)$. Science 1999, 285, 1042-1045. [CrossRef]

49. Das, A. A review of time economic innovative mnemonics in chemical education. Int. J. Phys. Chem. Educ. 2018, 10, 27-40. [CrossRef]

50. Paulson, J.F. Some negative-ion reactions with $\mathrm{CO}_{2}$. J. Chem. Phys. 1970, 52, 963-964. [CrossRef]

51. Christopher, P.; Xin, H.; Linic, S. Visible-light-enhanced catalytic oxidation reactions on plasmonic silver nanostructures. Nat. Chem. 2011, 3, 467-472. [CrossRef]

52. Li, S.M.; Zhang, B.; Gu, G.Q.; Xiang, X.C.; Zhang, W.H.; Shi, X.; Zhao, K.; Zhu, Y.F.; Guo, J.M.; Cui, P.; et al. Triboelectric plasma decomposition of $\mathrm{CO}_{2}$ at room temperature driven by mechanical energy. Nano Energy 2021, 88, 106287. [CrossRef] 